\title{
Measurement of asymmetric dimethylarginine, nitric oxide levels and total antioxidant capacity in experimental diabetic rats
}

\author{
ERHAN SÜRMELI, HAKAN TEKELI*, FUNDA KIRAL \\ Department of Biochemistry, Faculty of Veterinary Medicine, Adnan Menderes University, Aydin-Turkey \\ ${ }^{*}$ Golhisar Vocational High School of Health Service, Mehmet Akif Ersoy University, Burdur-Turkey
}

Sürmeli E., Tekeli H., Kiral F.

Measurement of asymmetric dimethylarginine, nitric oxide levels and total antioxidant capacity in experimental diabetic rats

Summary

The aim of this study is to investigate the status of oxidative stress and nitric oxide related parameters in diabetic rats. In experimental animals (12 rats) diabetes was induced by intraperitoneal injection of a single $50 \mathrm{mg} / \mathrm{kg}$ dose of streptozotocin. At the end of the experiment, in the blood serum of the control and experimental animals ADMA, NO was measured by using ELISA test. Serum levels of GSH, MDA and ceruloplasmin as well as TAC were detected in all animals. Compared to the control animals serum MDA levels in diabetic rats were remarkably and significantly $(\mathrm{P}<0.05)$ higher $(26.38 \pm 1.94 \mu \mathrm{mol} / \mathrm{L}$ and $42.23 \pm 1.24 \mu \mathrm{mol} / \mathrm{L}$, respectively). On the other hand, a statistically significant $(P<0.05)$ decrease from $4.39 \pm 0.15 \mathrm{mg} / \mathrm{dl}$ to $4.00 \pm 0.09 \mathrm{mg} / \mathrm{dl}$ was detected in serum GSH levels of the diabetic rats. Compared to the serum ceruloplasmin levels of healthy rats $(35.05 \pm 2.79 \mathrm{mg} / \mathrm{dl})$, diabetic rats showed a significant decrease $(P<0.001)$ in their serum ceruloplasmin concentration $(23.10 \pm 1.65 \mathrm{mg} / \mathrm{dl})$. Likewise, serum ADMA concentration of experimental animals $(7.26 \pm 0.86$ $\mathrm{ng} / \mathrm{ml})$ was higher than that of controls $(5.59 \pm 0.75 \mathrm{ng} / \mathrm{ml})$ but not significantly $(\mathrm{P}>0.05)$. As to serum TAC, compared to the control rats a statistically significant $(P<0.05)$ decline was observed in diabetic rats. Serum TAC of diabetic rats reduced from $1.01 \pm 0.06 \mathrm{mmol}$ trolox equivalent $/ \mathrm{L}$ to $0.87 \pm 0.03 \mathrm{mmol}$ trolox equivalent/L. Serum NO concentration of experimental animals $(30.42 \pm 2.48 \mu \mathrm{M} / \mathrm{ml})$ was significantly $(P<0.05)$ less than that of controls $(62.28 \pm 10.74 \mu \mathrm{M} / \mathrm{ml})$.

Keywords: Diabetic rats, total antioxidant capacity, asymmetric dimethylarginine

Diabetes is one of the systemic chronic metabolic diseases accompanied by hyperglycemia, dyslipidemia, glycosuria and much clinical and biochemical evidence (18). In diabetes, both acute and chronic complications can be seen in all organs. This is suggested to be caused by the tissue damage formed with autoxidation of glucose, protein glycation and auto-oxidative glycation with free radicals (23).

In studies showing the relationship between reactive oxygen species and diabetes and complications of diabetes, it has been emphasized that the tissue damage induced by non-enzymatic glycation, metabolic stress caused by changes in energy metabolism, hypoxia and ischemia-reperfusion increases free radical production and alters the antioxidant defense system (9).

Asymmetric dimethylarginine (ADMA) is a proteolytic by-product of arginine methylation found in the plasma, urine and tissues. ADMA is guanidino analogue of L-arginine and synthesized endogenously and metabolised by dimethylarginine dimethylaminohydrolases (DDAHs). In the protection of vascular tone and its structure, vasoactive mediators released from endothelial play an important role and nitric oxide (NO) is one of the most important of these mediators. Nitric oxide plays an important role in the regulation of vascular tone and platelet adhesion and aggregation. On the other hand, arginine and ADMA-DDAK pathway play an important role in the regulation of nitric oxide synthesis. ADMA is determined to be inhibiting the NOS enzyme (29).

Lipids are biomolecules that are most vulnerable to the effects of free radicals. Unsaturated bonds of cholesterol and fatty acids of cell membranes create peroxidation products by easily entering reaction with free radicals (6).

Under normal conditions, organisms have an antioxidant defense system struggling with free radicals caused by endogenous or exogenous reasons and 
oxidative stress developed due to these free radicals. Therefore, oxidative stress can also be viewed as an imbalance between the prooxidants and antioxidants in the body. The concentration of different reductantoxidant markers is considered an important parameter for assessing the prooxidant status in the body tissues. Several indicators of in vivo redox status are available, including the ratios of GSH to GSSG, NADH to NAD', as well as the balance between reduced and oxidized thioredoxin. The measurement of total antioxidant status may provide more valuable information compared to individual measurements of antioxidants. Total antioxidant capacity (TAC) reflects the total effect of all antioxidants in plasma and body fluids (11).

The aim of this study is to investigate the status of oxidative stress and nitric oxide related parameters in diabetic rats.

\section{Material and methods}

Experimental design and animals. This study was conducted on a total of 24 Sprague- Dawley rats with an age range of $8-10$ weeks and $245.50 \pm 14.5 \mathrm{~g}$ in weight. These rats were kept under standard light (12 hours of daylight/12 hours of darkness) and temperature $\left(22^{\circ} \mathrm{C}\right)$ with sufficient water and food at the Experimental Animals Laboratory of Adnan Menderes University, Faculty of Veterinary Medicine, and then adapted to the environment by taking them one week before the start of the study. The animals used in the study were divided into 2 groups: as control $(\mathrm{n}=12)$ and diabetic $(\mathrm{n}=12)$ animals. The study was evaluated by the Local Ethics Committee of Animal Experiments in Adnan Menderes University and approved by the ethics committee on 01/01/2011 with decision number 2011/026.

Sample collection and biochemical assays. In order to create experimental diabetes, $0.01 \mathrm{M}$ sodium citrate buffer (pH: 4.5) was injected to the experimental group with streptozotocin $50 \mathrm{mg} / \mathrm{kg}$ intraperitoneally. Streptozotocin injection may result in fatal hypoglycemia related to massive insulin release. To prevent hypoglycemia, rats were kept on a $5 \%$ glucose solution diet for $24 \mathrm{~h}$ after the injection. Similar to the experimental group of animals, a $0.01 \mathrm{M}$ sodium citrate buffer was given to the control group intraperitoneally. After 28 days following the injection, the animals were fasted for 12 hours and serum glucose levels were measured. Rats with blood glucose levels $>11 \mathrm{mmol} / \mathrm{L}$ (higher than $200 \mathrm{mg} / \mathrm{dl}$ ) were considered diabetic and were used for the study. After diagnosing all animals in the experimental group with diabetes, blood samples were collected from their heart under ether anesthesia and then they were euthanized by cervical dislocation. Blood was then centri- fuged at 4,000 $\mathrm{g}$ for $10 \mathrm{~min}$ to remove red blood cells and recover serum.

Serum asymmetric dimethylarginine (ADMA) was manually tested in the ELISA device by Elisa commercial kit (Cusabio Biotech, Cat No: CSBE08896r). Serum nitric oxide (NO) levels were measured by 'Nitric Oxide Colorimetric Assay' (Roche Cat. No: 1756281) method. The value of nitrogen monoxide was determined by the measurements of serum nitrite. Plasma total antioxidant capacity (TAC) levels were studied by the method developed by Erel (10) with Rel Assay (Rel Assay Diagnostics, Türkiye, lot no: RL002) kits.

The lipid peroxidation of serum was measured by the Tris-Boric Acid (TBA) (the method described by Yoshioka et al. (33)). Malondialdehyde (MDA), formed from the breakdown of polyunsaturated fatty acids, was considered as an index for the peroxidation reaction. The absorbance of the action product of MDA with TBA was measured at $532 \mathrm{~nm}$. Quantization was based upon a molar extinction coefficient of $1.56 \times 105 \mathrm{M}-1 \mathrm{~cm}-1$.

Serum glutathione (GSH) concentration was assayed by the method of Beutler et al. (5). GSH concentration detected in the serum was measured spectrophotometrically at $412 \mathrm{~nm}$.

The serum ceruloplasmin levels were determined by measuring p-phenylenediamine oxidase activity as described previously by Sunderman and Nomoto (27). Briefly, $5 \mathrm{ml}$ phenylenediamine substrate ( $\mathrm{pH} 5.6$ ) was added to the curve and test tubes. One microlitre sodium azide solution was then added into the curve tube only. This was followed by the addition of $0.1 \mathrm{ml}$ of sera to both the curve and test tubes. Samples were mixed and kept at $37.8^{\circ} \mathrm{C}$ for $15 \mathrm{~min}$. Finally, $1 \mathrm{ml}$ of the sodium azide solution was added to the test tube only, and all samples were then incubated at room temperature for $15 \mathrm{~min}$. The optical density was measured at $546 \mathrm{~nm}$ using a spectrophotometer (Shimadzu, UV-160).

Statistical analysis. The findings of the study were analyzed by using an SPSS 11.5 (Statistical Package for the Social Sciences) program. The significance level of the differences were determined by using Independent Samples Test.

\section{Results and discussion}

The results of this study are shown in Table 1. As a result of this study, serum ADMA concentration of experimental animals $(7.26 \pm 0.86 \mathrm{ng} / \mathrm{ml})$ was higher than that of controls $(5.59 \pm 0.75 \mathrm{ng} / \mathrm{ml})$ but not significantly $(\mathrm{P}>0.05)$. Serum NO concentration of experimental animals $(30.42 \pm 2.48 \mu \mathrm{M} / \mathrm{ml})$ was significantly $(\mathrm{P}<0.05)$ less than that of controls $(62.28$

Tab. 1. Control and experimental groups related to the serum ADMA, NO, MDA, GSH, ceruloplasmin and total antioxidant activity levels

\begin{tabular}{|l|c|c|c|c|c|c|}
\hline \multicolumn{1}{|c|}{ Groups } & ADMA $(\mathrm{ng} / \mathrm{ml})$ & NO $(\mu \mathrm{M} / \mathrm{ml})$ & $\begin{array}{c}\text { TAC (mmoltrolox } \\
\text { equivalent) }\end{array}$ & GSH (mg/dl) & $\begin{array}{c}\text { MDA ( } \mu \text { mol/L) } \\
\text { Ceruloplasmin } \\
(\mathrm{mg} / \mathrm{dl})\end{array}$ \\
\hline Control $(\mathrm{n}=12)$ & $5.59 \pm 0.75$ & $62.28 \pm 10.74$ & $1.01 \pm 0.06$ & $4.39 \pm 0.1$ & $26.38 \pm 1.9$ & $35.05 \pm 2.8$ \\
\hline Diabetic rats $(\mathrm{n}=12)$ & $7.26 \pm 0.86$ & $30.42 \pm 2.48^{*}$ & $0.87 \pm 0.03^{*}$ & $4.00 \pm 0.9^{*}$ & $42.2 \pm 1.3^{*}$ & $23.10 \pm 1.7^{*}$ \\
\hline
\end{tabular}

Explanations: * $\mathrm{P}<0.05, * * \mathrm{P}<0.001$ 
$\pm 10.74 \mu \mathrm{M} / \mathrm{ml})$. As to serum TAC, compared to the control rats a statistically significant $(\mathrm{P}<0.05)$ decline was observed in diabetic rats. Serum TAC of diabetic rats reduced from $1.01 \pm 0.06 \mathrm{mmol}$ trolox equivalent $/ \mathrm{L}$ to $0.87 \pm 0.03 \mathrm{mmol}$ trolox equivalent $/ \mathrm{L}$.

Compored to the control animals serum MDA levels in diabetic rats were remarkably and significantly $(\mathrm{P}<0.05)$ higher $(26.38 \pm 1.94 \mu \mathrm{mol} / \mathrm{L}$ and 42.23 $\pm 1.24 \mu \mathrm{mol} / \mathrm{L}$, respectively). On the other hand, a statistically significant $(\mathrm{P}<0.05)$ decrease from $4.39 \pm 0.15 \mathrm{mg} / \mathrm{dl}$ to $4.00 \pm 0.09 \mathrm{mg} / \mathrm{dl}$ was detected in serum GSH levels of the diabetic rats. Compared to the serum ceruloplasmin levels of healthy rats $(35.05$ $\pm 2.79 \mathrm{mg} / \mathrm{dl}$ ), diabetic rats showed a significant decrease $(\mathrm{P}<0.001)$ in their serum ceruloplasmin concentration $(23.10 \pm 1.65 \mathrm{mg} / \mathrm{dl})$.

Insulin-dependent diabetes is becoming more common today with the influence of living conditions and therefore it is a widely studied pathology with its treatment and mechanisms of action. The data obtained by the preliminary work on animal experiments in this field is used in applications in humans (28).

Streptozotocin (STZ) reduces biosynthesis and secretion of insulin by disrupting glucose oxidation (4). The severity and duration of hyperglycemia depends on the dosage of the drug and type of laboratory animals (28). Since we aimed to have animals with diabetes, the STZ method was selected and a single dose was applied. Our results show that the smallest dose of i.p. $50 \mathrm{mg} / \mathrm{kg} \mathrm{STZ}$ is enough to have animals with diabetics which is in accordance with the literature (13).

Free radicals are continuously synthesized in the body during normal metabolic processes. As a result of protein glycation and auto-oxidation of glucose in diabetes, the formation of free radicals increases. Increased oxidative stress is thought to play an important role in the etiopathogenesis of chronic complications of diabetes (3). Oxidative stress is known to be associated with metabolic or vascular diseases (30). Increased concentrations of glucose in diabetes result in deterioration of the balance between antioxidants and prooxidants and thus lead to increased oxidative stress (12).

Haluzik and Nedvidkova (14) detected increase in MDA concentration of kidney tissue and reduction in superoxide dismutase (SOD) and catalase activities in rats with diabetes induced by STZ. Yilmaz et al. (32) found an increase in the level of MDA in the liver tissue of 8-week-old rats with STZ diabetes, and suggested that the increased oxidative stress was responsible for diabetic cardiomyopathy, nephropathy and vascular complications. Akkaya and Çelik (2) investigated the relationship between free radicals and antioxidants in healthy and diabetic rats and reported an increased in the MDA levels and reduction in the homocysteine, leptin and vitamin $\mathrm{C}$ levels of diabetic rats compared to the rats in the control group. In this study, MDA levels of rats with diabetes were found to be increased compared to the control group. These results are consistent with the results of earlier studies in the literature.

Opposite results were found in studies conducted on plasma ADMA levels in patients with type 2 diabetes mellitus. For example, Krzyzanowska et al. (16) reported increased ADMA levels in patients with type 2 diabetes, whereas Paiva et al. (22) found reduced ADMA levels in patients with type 2 diabetes and suggested that this may be caused by an increased glomerular filtration rate and poor glycemic control. In another study conducted by Lin et al. (17), the nitric oxide synthase pathway, which was deteriorated in Diabetes Mellitus, was examined and plasma ADMA levels were found to be higher in streptozotocin-induced diabetic rats.

Nitric oxide is a molecule that can play an important role as both pro-oxidant and anti-oxidant (30). In the literature, different results have been reported about NO levels in diabetes. Although Abou-Seif and Youssef (1) have found high plasma NO amounts in diabetic patients, Mohan and Das (19) reported that diabetes decreases plasma NO amounts in rats, and their NO levels can be increased by insulin and their increased MDA values can also be reduced.

Elabbady et al. (8) suggested a mechanism where NO may take place in the etiology of type I diabetes. Accordingly, macrophages rather CD4 T cells activated due to an autoimmune reason damage islet cells of the pancreas by causing large amounts of NO release. Khandelwal et al. (15) stated that synthesis of different isoforms of nitric oxide synthase enzyme may be increased or reduced depending on age, type of tissue and metabolic changes caused by diabetes in the tissue.

Measurement of the total antioxidant status may provide more valuable information compared to individual measurements of each antioxidant and, on account of this, total antioxidant capacity measurements that give the value of total antioxidants in the blood have become more common rather than individual antioxidant measurements. Therefore, in this study, we measured the total antioxidant capacity in rats with diabetes by using the most popular method developed by Erel (10).

Opara et al. (21) found serum total antioxidant levels lower in diabetes mellitus patients with and without proteinuria compared to the controls. Shin et al. (25) have found an inverse relationship between insulin resistance and plasma total antioxidant capacity, $\beta$-carotene and $\alpha$-tocopherol levels. Dosoo et al. (7) have reported that the total antioxidant capacity in Non-IDMM patients reduced in an inverse proportion with fasting blood glucose.

Yanwen et al. (31) found that GSH levels were reduced in diabetic rats compared to the control group and likewise GSH levels were reduced in STZ-induced diabetic rats compared to the control group (24). Subramanian et al. (26) stated that ceruloplasmin levels were reduced in diabetic rats compared to the control group. In our study, GSH and ceruloplasmin levels were found to be reduced in diabetic rats compared 
to the control group. These results are consistent with results of the earlier studies in the literature.

In this study, according to the findings obtained from the streptozotocin induced experimental diabetic model, increased glucose levels in diabetic rats cause oxidative stress and lipid peroxidation by increasing plasma MDA value and lead to a reduction in total antioxidant capacity. In addition, increased glucose levels cause an increase in the serum ADMA levels by affecting hyperglycemia ADMA metabolism and lead to a reduction in NO levels. DDAH is an endogenous inhibitor of NOS, so ADMA-DDAH pathway plays important role in control of $\mathrm{NO}$ in vivo. Although ADMA has been identified as a risk factor for endothelial dysfunction associated with DM, it is known that in diabetic patients with foot ulcers, decreased levels of $\mathrm{NO}$ and increased levels of ADMA in wound fluid are indicators of impaired wound healing. Since free radicals may play a role in the pathogenesis of diabetes and formation of complications, oral antidiabetic, insulin and various agents as well as antioxidant agents and vitamins can be used to prevent occurrence and spread of the disease.

\section{References}

1. Abou-Seif M. A., Youssef A. A.: Evaluation of some biochemical changes in diabetic patients. Clin. Chim. Acta 2004, 346, 161-170.

2. Akkaya H., Çelik S.: Ratlarda diyabet öncesi ve sonrası oksidan-antioksidan durum, F.Ü. Sağ. Bil. Vet. Der. 2010, 24, 5-10.

3. Baynes $J$. W., Thorpe S. R.: Role of oxidative stress in diabetic complications: A new perspective on an old paradigm. Diabetes 1999, 48, 1-9.

4. Bedoya F. J., Solano F., Lucas M.: N-monomethyl-arginine and nicotinamide prevent streptozotocine-induced double strand DNA break formation in pancreatic islets. Experientia 1996, 52, 344-347.

5. Beutler E., Dubon O., Kelly B. M.: Improved method for the determination of blood glutathione. J. Lab. Clin. Med. 1963, 61, 882-888.

6. Byung P. Y.: Celluler defences agains damage from reactive species. Physiol. Rev. 1994, 74, 139-172.

7.Dosoo D. K., Rana S. V., Offe-Amoyaw K., Tete-Donkor D., Maddy S. Q.: Total antioxidant status in non-insulin-dependent diabetes mellitus patients in Ghana. West Afric J. Med. 2001, 20, 184-186.

8. Elabbady A. A., Gagnon C., Hassouna M. M.: Diabetes mellitus increase NO synthase in penises but not in majority of rats. Br. J. Urol. 1995, 76, 196-202.

9. Elmalı E., Altan N., Bukan N.: Effect of sulphonylurea glibenclamide on liver and kidney antioxidant enzymes in streptozotocin-induced diabetic rats. Drugs R. D. 2004, 5, 203-208.

10. Erel O.: A novel automated method to measure total antioxidant response against potent free radical reactions. Clin. Biochem. 2004, 37, 112-119.

11. Ghiselli A., Serafini M., Natella F., Scaccini C.: Total antioxidant capacity as a tool to assess redox status: critical view and experimental data. Free Radic. Biol. Med. 2000, 29, 1106-1114

12. Gmieniczek A., Hopkala H., Wojtowicz Z., Nieradko M.: Differences in antioxidant status in skeletal muscle tissue in experimental diabetes. Clin. Chim. Acta 200, 314, 39-45.

13. Gönül B., Demiröz A. S., Özer Ç.: The oxidant/antioxidant capacity of diabetic rat liver tissue treated with benfluorex. Faseb J. 2005, 19, A 1531.

14. Haluzik M., Nedvidkova J.: The role of nitric oxide in the development of streptozotocine induced diebetes mellitus: experimental and clinical implications. Physiol. Res. 2000, 49, 37-42.

15. Khandelwal R. L., Gupta D., Sulakhe P. V.: Decreased activity and impaired induction of nitric oxide synthase by lipopolysaccharides in streptozotocineinduced diabetic rats. Bioc. Bioph. Acta 2003, 1620, 259-266.

16. Krzyzanowska K., Mittermayer F., Krugluger W., Schnack C., Hofer M., Wolzt M., Schernthaner G.: Asymmetric dimethylarginine is associated with macrovascular disease and total homocysteine in patients with type 2 diabetes. Atherosclerosis 2006, 189, 236-240.

17. Lin K. Y., Ito A., Asagami T., Tsao P. S., Adimoolam S., Kimoto M., Tsuji M., Reaven G. M., Cooke J. P.: Impaired nitric oxide synthase pathway in diabetes mellitus: role of asymmetric dimethylarginine and dimethylarginine dimethylaminohydrolase. Circulation 2002, 106, 987-992.

18. Mesa J., Salcedo D., Calle H., Delgado E., Novoa J., Hawkins F., Navarrete G. S., Parramon M., Acosta D.: Detection of ketonemia and its relationship with hyperglycemia in type I Diabetic patients. Diabetes Res. Clin. Pract. 2006, 72, 292-297.

19. Mohan K., Das U. N.: Effect of L-arginine-nitric oxide system on the metabolism of essential fatty acids in chemical-induced diabetes mellitus. Prostaglandins Leukot. Essent. Fatty Acids 2000, 62, 35-46.

20. Nukatsuka M., Yoshimura Y., Nishida M., Kawadw J.: Importance of the concentration of ATP in rat pancreatic beta cells in the mechanism of streptozotocine-induced cytotoxicity. J. Endocrinol. 1990, 127, 161-165.

21. Opara E. C., Abdel-Rahman E., Soliman S., Kamel W. A., Souka S., Lowe J. E., Abdel-Aleem $S$.: Depletion of total antioxidant capacity in type 2 diabetes. Metabolism 1999, 48, 1414-1417.

22. Paiva H., Lehtimaki T., Laakso J., Ruokonen I., Rantalaiho V., Wirta O., Pasternack A., Laaksonen R.: Plasma concentrations of asymmetric-dimethylarginine in type 2 diabetes associate with glycemic control and glomerular filtration rate but not with risk factors of vasculopathy. Metabolism 2003, 52 , 303-307.

23. Serafini M., Del Rio D.: Understanding the association between dietary antioxidants, redox status and disease: is the total antioxidant capacity the right tool? Redox Rep. 2004, 9, 145-152.

24. Shanmugam K. R., Mallikarjuna K., Kesireddy M., Reddy K. S.: Neuroprotective effect of ginger on anti-oxidant enzymes in streptozotocin-induced diabetic rats. Food Chem. Toxicol. 2011, 41, 893-897.

25. Shin M.-J., Park E., Lee J. H., Chung N.: Relationship between insulin resistance and lipid peroxidation and antioxidant vitamins in hypercholesterolemic patients. Ann. Nutr. Metab. 2006, 50, 115-120.

26. Subramanian V., Leelavinothan P., Ganesan S.: Effect of Phaseolus vulgaris on Circulatory Antioxidants and Lipids in Rats with Streptozotocin Induced Diabetes. J. Med. Food. 2002, 5, 97-103.

27. Sunderman F. W., Nomoto S.: Measurement of human serum ceruloplasmin by its p-phenylene-diamine oxidase activity. Clin. Chem. 1970, 16, 903-910.

28. Szkudelski T.: The mechanism of alloxan and streptozotocin action in B cells of the rat pancreas. Physiol. Res. 2001, 50, 536-546.

29. Vallance P., Leiper J.: Cardiovascular Biology of the Asymmetric Dimethylarginine: Dimethylarginine Dimethylaminohydrolase Pathway. Arterioscler Thromb. Vasc. Biol. 2004, 24, 1023-1030.

30. Wiernsperger N. F.: Oxidative stress as a therapeutic target in diabetes: revisiting the controversy. Diabetes Metab. 2003, 29, 1-14.

31. Yanwen W., Tony C., Benjamin P., Cécile B., Ling $Q$. : Hypoglycemic and insulin-sensitizing effects of berberine in high-fat diet- and streptozotocininduced diabetic rats. Metabolism 2011, 60, 298-305.

32. Yılmaz H. R., Uz E., Yücel N., Altuntaș I., Ozçelik N.: Protective effect of caffeic acid phenethyl ester (CAPE) on lipid peroxidation and antioxidant enzymes in diabetic rat liver. J. Biochem. Mol. Toxicol. 2004, 18, 234-238.

33. Yoshoiko T., Kawada K., Shimada T.: Lipit peroxidation in maternal and cord blood and protective mechanism aganist actived-oxygen toxicity in the blood. Am. J. Obstet. Gynecol. 1979, 135, 372-376.

Corresponding author: Hakan TEKELİ, Mehmet Akif Ersoy University, Golhisar Vocational High School of Health Service, Burdur-Turkey; e-mail:hakantekeli85@hotmail.com 